\title{
Effects of Positive Pressure Ventilation on Intrarenal Blood Flow in Infant Primates
}

\author{
EDDIE S. MOORE, ${ }^{(26)}$ MAURINA B. GALVEZ, JOHN B. PATON, DAVID E. FISHER, \\ AND RICHARD E. BEHRMAN \\ Department of Pediatrics, University of Mlinois College of Medicine, Chicago, Illinois, USA
}

\section{Extract}

Measurement of intrarenal distribution of renal blood flow by injection of radionuclides in 3-5-day-old infant monkeys showed a preponderance of outer cortical over inner cortical flow with flow rates of 4.23 and $2.54 \mathrm{ml} / \mathrm{min} / \mathrm{g}$, respectively. Intermittent positive pressure ventilation (IPPV) causes a reversal of this flow pattern. The theoretical difference in nephron function in these two areas suggests that this reversal in intrarenal flow induced by IPPV may have important clinical implications.

\section{Speculation}

Extrarenal stimuli such as IPPV causes a redistribution of intrarenal blood flow in infant primates. Any stimuli that results in increased production of epinephrine or similar compounds may be responsible for this redistribution by a local effect on outer cortical blood vessels. Our data further suggest that antidiuretic hormone may influence intrarenal blood flow in addition to altering tubular membrane permeability.

\section{INTRODUCTION}

Recent studies have demonstrated that renal blood flow in early infancy is low when compared with that in the older child and adult. Gruskin et al. (7) have shown in infant piglets that this low renal blood flow increases by a fall in intrinsic renal vascular resistance which results in a greater percentage of the cardiac output going to the kidneys. Jose and colleagues (11) subsequently demonstrated by using ${ }^{33} \mathrm{Xe}$ washout techniques, that cortical flow (component I) was low when compared with medullary flow (component $I I$ ) in puppies up to 4 months of age. After 4 months of age, component I flow and total renal blood flow increased markedly. These authors concluded that there is relative underperfusion of the renal cortex in infant puppies and this is a major factor for the low renal blood flow in that age group.

The importance of intrarenal distribution of renal blood flow is controversial. Hollenberg and Herd (8) have noted that although total renal blood flow may be reduced severely in chronic renal disease, adequate renal function may persist, whereas a similar decrease in total renal blood flow in acute renal failure may be associated with oliguria and renal insufficiency. The difference in renal function in these conditions may be explained in part by the presence of normal rates of blood flow and glomerular filtration in some portions of the cortex in chronic renal failure but abnormally low cortical flow rates in patients with acute failure. Horster and Thurau (9) found that superficial cortical and juxtamedullary nephrons in adult rats have different functional capacities. It can be speculated that the occurrence of decreased urine flow might result from redistribution of blood to inner cortical nephrons with possible greater reabsorptive capacity. The extent and character of overall renal function may therefore be in part dependent upon intrarenal distribution as well as on total renal blood flow. Although the studies of Jose et al. (11) demonstrated a low cortical flow and low total renal blood flow in infant puppies, few studies have been done in infants to measure the effect on intrarenal flow to various stimuli and how this would affect overall renal function. Intermittent positive pressure ventilation is an extensively used therapeutic procedure in pediatrics. Decreased urine flow is known to occur in some patients receiving $\operatorname{IPPV}(13,20)$. We speculated that this decreased urine flow might result from redistribution of renal blood flow as discussed previously. The purpose of this study, therefore, was to measure basal intrarenal distribution of renal blood flow in infant primates and to study changes in distribution of response to the stress of IPPV. Our findings demonstrate that the pattern of intrarenal blood flow distribution in resting infant monkeys is similar to the adult with a preponderance of outer cortical over inner cortical flow. Assisted ventilation was found to result in a redistribution of this flow which theoretically would affect renal function.

\section{MATERIALS AND METHODS}

Seventeen infant Macacca sp. monkeys born in the caged primate breeding facility at the University of Illinois College of Medicine were used in this study. The infants were born by spontaneous vaginal delivery and were studied between 3 and 5 days of age. All infants were mature by weight and gestational age.

For surgery each infant was restrained comfortably on a padded frame in the supine position. A catheter (PV 3) was inserted into a femoral artery and advanced to the left ventricle. The placement of this catheter was confirmed by pressure recordings and/or fluoroscopy. A second arterial catheter was advanced from the femoral artery and placed with its tip at the level of the diaphragm. This catheter was used for arterial blood sampling and aortic pressure recordings. An additional catheter was inserted into the inferior vena cava via a femoral vein for infusion and venous blood sampling. After repair of skin incisions, the infant was secured in the prone position on a toweling roll and placed in an incubator with room air at constant temperature and humidity. The period of recovery was from 18 to $24 \mathrm{hr} ; 100 \mathrm{ml} / \mathrm{kg} / 24 \mathrm{hr}$ of 
$10 \%$ glucose in water was given intravenously. Penicillin $(100,000$ units $/ \mathrm{kg})$ and Kanamycin $(15 \mathrm{mg} / \mathrm{kg})$ were given as a single injection to each infant after surgery.

On the following day, the catheters were flushed with saline and control blood gases and flow measurements were obtained. A modification of the radionuclide microsphere method described by Rudolph and Heymann (19), 20-25,000 microspheres, $50 \mu \mathrm{m}$ in diameter, were injected slowly into the left ventricle, was utilized to estimate cardiac output and organ blood flow. Simultaneously, approximately $1 \mathrm{ml}$ blood was withdrawn over $1 \mathrm{~min}$ from the descending aorta using a constant speed pump. Inasmuch as adequate mixing of microspheres and blood has been shown to take place in the left ventricle, the withdrawn sample of blood which contains microspheres can be quantitated and is directly proportional to cardiac output.

Control measurements of cardiac output and distribution of renal blood flow were done by injection of microspheres labeled with ${ }^{46} \mathrm{Sc}$. Injection of three different nucleotides over 4 days into six control infants showed no significant affect on renal flow by this procedure. After determination of control values, an endotracheal tube was passed and the infant was placed on a mechanical respirator with IPPV at less than 10 $\mathrm{mm} \mathrm{Hg}$ but sufficient to cause expansion of the chest without significant change in blood gases. The IPPV was continued for $6 \mathrm{hr}$. Arterial $\mathrm{pH}, \mathrm{P}_{\mathrm{CO}_{2}}$, and base excess were monitored frequently during ventilation. After ventilation, a second injection of a different labeled nucleotide $\left({ }^{125} I\right)$ was made to measure any changes in cardiac output and distribution of cortical flow. Blood pressure was measured using a Statham pressure transducer and recorded on a Sanborn recorder.

After each experiment the monkeys were killed by injection of sodium pentobarbital. All organs except the kidneys were removed, weighed, and ashed at $375^{\circ}$ for determination of total body radioactivity. Separate experiments were performed to assure that there was no loss of radioactivity at this temperature. The ashed tissues were then placed in glass vials and radioactivity measured in a $\gamma$ counter (22). After counting total kidney radioactivity, the kidneys were dissected along the sagittal plane according to the method of Katz et al. (12). The capsule was removed and the cortex divided into equal portions of outer and inner cortex using a dissecting microscope (23). Careful dissection was done to avoid including any medullary tissue with the inner cortical slices. The tissue slices were weighed on a Mettler balance and the radioactivity for each isotope in the slices counted. Slices were taken from both kidneys for comparison of results. The blood flow to the total cortex and segments of the cortex were calculated based on weight and radioactivity. The theoretical consideration as to whether or not selected sections of the cortex obtained in the described manner represents flow to the kidney as a whole has been discussed by Katz et al. (12).

The radioactivity due to each isotope in each kidney was calculated using the method of Rudolph and Heymann (18). Cardiac output, total kidney, and regional cortical blood flows were calculated from the following equations

Cardiac output

$$
\frac{\text { Rate aortic blood withdrawal }(\mathrm{ml} / \mathrm{min})}{\text { Cardiac output }(\mathrm{ml} / \mathrm{min})}=\frac{\begin{array}{c}
\gamma \text { Activity of blood } \\
\text { withdrawn from aorta }
\end{array}}{\text { Total body } \gamma \text { activity }}
$$

\section{Renal blood flow}

Renal blood flow $(\mathrm{ml} / \mathrm{min})=$ Kidney $\gamma$ activity

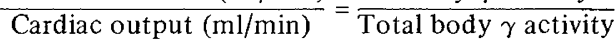

$$
\begin{aligned}
& \text { Regional cortical flow } \\
& \frac{\text { Renal blood flow }(\mathrm{ml} / \mathrm{min})}{\text { Renal } \gamma \text { activity }(\mathrm{dpm} / \mathrm{g})}=\frac{\text { Regional cortical flow }(\mathrm{ml} / \mathrm{min} / \mathrm{g})}{\text { Regional cortical } \gamma \text { activity }(\mathrm{dpm} / \mathrm{g})}
\end{aligned}
$$

Statistical analysis of mean values was by means of the Student paired $t$ test.

\section{RESULTS}

The mean control arterial $\mathrm{pH}$, base excess and standard bicarbonate were $7.385,-3.60$, and 20.47 , respectively. These control values indicated the stability of the infants before ventilation. The mean control $\mathrm{P}_{\mathrm{O}_{2}}$ was $97.86 \mathrm{~mm} \mathrm{Hg}$ and the

\begin{tabular}{|c|c|c|c|c|c|c|c|c|}
\hline \multirow[b]{2}{*}{ Study } & \multirow[b]{2}{*}{ Weight, g } & \multicolumn{2}{|c|}{ Cardiac output } & \multirow{2}{*}{$\begin{array}{l}\text { Total RBF, } \\
\mathrm{ml} / \mathrm{min} / \mathrm{gm}\end{array}$} & \multirow{2}{*}{$\begin{array}{l}\text { Cardiac } \\
\text { output, } \%\end{array}$} & $\mathrm{OC}$ & IC & \multirow[b]{2}{*}{$\mathrm{OC} / \mathrm{IO}$} \\
\hline & & $\mathrm{ml} / \mathrm{min}$ & $\mathrm{ml} / \mathrm{min} / \mathrm{kg}$ & & & \multicolumn{2}{|c|}{$\mathrm{ml} / \mathrm{min} / \mathrm{g}$} & \\
\hline 1 & 530 & 84.43 & 159.30 & 2.62 & 10.21 & 4.35 & 3.24 & 1.34 \\
\hline 2 & 500 & 101.62 & 203.24 & 2.62 & 10.45 & 5.45 & 1.22 & 4.46 \\
\hline 3 & 540 & 70.26 & 130.11 & 1.76 & 12.89 & 4.31 & 1.76 & 2.45 \\
\hline 4 & 400 & 82.70 & 206.75 & 4.69 & 12.45 & 8.19 & 7.28 & 1.13 \\
\hline 5 & 530 & 63.91 & 120.59 & 2.11 & 10.72 & 3.57 & 2.25 & 1.59 \\
\hline 6 & 390 & 54.77 & 140.44 & 2.81 & 15.34 & 7.58 & 2.96 & 2.56 \\
\hline 7 & 490 & 160.17 & 326.88 & 4.22 & 11.16 & 10.62 & 2.46 & 4.31 \\
\hline 8 & 450 & 20.24 & 44.90 & 1.01 & 17.10 & 1.43 & 1.20 & 1.19 \\
\hline 9 & 490 & 48.14 & 98.24 & 2.26 & 15.89 & 4.19 & 0.64 & 6.55 \\
\hline 10 & 420 & 46.94 & 111.76 & 2.54 & 11.03 & 4.78 & 2.29 & 2.09 \\
\hline 11 & 650 & 110.50 & 170.00 & 1.54 & 6.78 & 3.49 & 2.94 & 1.18 \\
\hline 12 & 490 & 81.54 & 166.41 & 1.99 & 9.45 & 4.08 & 1.68 & 5.29 \\
\hline 13 & 590 & 74.54 & 126.33 & 1.92 & 7.02 & 8.89 & 1.63 & 2.49 \\
\hline 14 & 470 & 93.17 & 198.23 & 2.43 & 11.86 & 8.51 & 2.45 & 3.47 \\
\hline 15 & 620 & 102.82 & 165.83 & 1.53 & 7.94 & 4.12 & 3.81 & 1.08 \\
\hline$\overline{\mathrm{x}}$ & 502 & 80.14 & 159.00 & 2.46 & 11.57 & 4.23 & 2.54 & 2.56 \\
\hline $\mathrm{SE}$ & 14.54 & 7.18 & 13.08 & 0.21 & 0.65 & 0.74 & 0.28 & 0.34 \\
\hline
\end{tabular}
mean $\mathrm{P}_{\mathrm{CO}_{2}}$ was $35.20 \mathrm{~mm} \mathrm{Hg}$. These arterial blood gases are similar to those reported previously in unstressed Macacca sp. monkeys (1). The mean weight of these infants was $502 \mathrm{~g}$

Table 1. Control flow measurements ${ }^{1}$

${ }^{1} \mathrm{RBF}$ : renal blood flow; OC: outer cortex; IC: inner cortex. 
Table 2. Flow measurements after assisted ventilation ${ }^{1}$

\begin{tabular}{|c|c|c|c|c|c|c|c|}
\hline \multirow[b]{2}{*}{ Study } & \multicolumn{2}{|c|}{ Cardiac output } & \multirow{2}{*}{$\begin{array}{l}\text { Total RBF, } \\
\mathrm{ml} / \mathrm{min} / \mathrm{g}\end{array}$} & \multirow{2}{*}{$\begin{array}{c}\text { Cardiac } \\
\text { output, } \%\end{array}$} & $\mathrm{OC}$ & $\mathrm{IC}$ & \multirow[b]{2}{*}{$\mathrm{OC} / \mathrm{IC}$} \\
\hline & $\mathrm{ml} / \mathrm{min}$ & $\mathrm{ml} / \mathrm{min} / \mathrm{kg}$ & & & \multicolumn{2}{|c|}{$\mathrm{ml} / \mathrm{min} / \mathrm{g}$} & \\
\hline 1 & 52.25 & 100.47 & 0.86 & 5.12 & 0.37 & 0.95 & 0.39 \\
\hline 2 & 59.28 & 118.56 & 0.84 & 5.83 & 0.24 & 3.21 & 0.08 \\
\hline 3 & 91.35 & 169.17 & 1.81 & 12.44 & 1.96 & 1.64 & 1.20 \\
\hline 4 & 27.20 & 68.00 & 1.08 & 8.44 & 1.63 & 2.33 & 0.70 \\
\hline 5 & 32.80 & 59.64 & 1.01 & 13.92 & 0.84 & 2.31 & 0.36 \\
\hline 6 & 30.16 & 77.33 & 0.58 & 5.75 & 0.29 & 0.93 & 0.31 \\
\hline 7 & 59.97 & 122.39 & 0.86 & 6.08 & 0.66 & 1.23 & 0.54 \\
\hline 8 & 54.59 & 122.20 & 1.23 & 7.69 & 0.61 & 1.21 & 0.51 \\
\hline 9 & 35.27 & 71.98 & 0.53 & 5.08 & 0.32 & 0.32 & 1.01 \\
\hline 10 & 33.14 & 78.90 & 0.60 & 3.66 & 0.32 & 1.00 & 0.32 \\
\hline 11 & 88.10 & 135.53 & 1.25 & 6.89 & 1.96 & 2.97 & 0.66 \\
\hline 12 & 48.58 & 99.14 & 1.15 & 9.18 & 3.57 & 2.51 & 1.42 \\
\hline 13 & 50.10 & 84.92 & 0.34 & 3.56 & 0.69 & 0.57 & 1.22 \\
\hline 14 & 41.73 & 88.78 & 0.59 & 6.50 & 0.99 & 2.18 & 0.46 \\
\hline 15 & 69.06 & 111.39 & 0.79 & 6.20 & 0.70 & 1.54 & 0.45 \\
\hline$\overline{\mathrm{X}}$ & 51.64 & 100.56 & 0.91 & 7.09 & 1.01 & 1.66 & 0.64 \\
\hline $\mathrm{SE}$ & 5.11 & 7.64 & 0.09 & 0.75 & 0.24 & 0.23 & 0.10 \\
\hline
\end{tabular}

${ }^{1}$ RBF: renal blood flow; OC: outer cortex; IC: inner cortex.

Table 3. Mean $\pm S E$ arterial pressure and renal vascular resistance

\begin{tabular}{|c|c|c|c|c|}
\hline & $\begin{array}{c}\text { Cardiac output, } \\
\mathrm{ml} / \mathrm{min}\end{array}$ & $\begin{array}{c}\text { Mean aortic } \\
\text { pressure } \\
\text { mm Hg }\end{array}$ & $\begin{array}{l}\text { Total RBF, } \\
\mathrm{ml} / \mathrm{min} / \mathrm{g}\end{array}$ & $\begin{array}{l}\text { Renal vascular } \\
\text { resistance, } \\
\mathrm{mm} \mathrm{Hg} / \mathrm{ml} / \mathrm{g}\end{array}$ \\
\hline Control & $80.14 \pm 7.18$ & $63 \pm 1.97$ & $2.46 \pm 0.21$ & $27.12 \pm 4.84$ \\
\hline Ventilation & $51.64 \pm 5.11$ & $61 \pm 1.55$ & $0.91 \pm 0.09$ & $56.41 \pm 5.87$ \\
\hline Statistical comparison & $P<0.005$ & $P>0.05$ & $P<0.001$ & $P<0.005$ \\
\hline
\end{tabular}

(Table 1) and is comparable with that reported for other Macacca sp. monkeys in this age group. After ventilation, the mean arterial $\mathrm{pH}$ was 7.423 and was not significantly different from the control value. The $\mathrm{P}_{\mathrm{O}_{2}}, \mathrm{P}_{\mathrm{CO}_{2}}$, base excess, and standard bicarbonate after ventilation were 93.52, 41.03, -2.56 , and 26.96 , respectively. These values also were not significantly different from control values. Thus we were able to maintain assisted ventilation without significantly altering acid-base status. Therefore, acid-base changes or asphyxia per se could not have played a major role in the results in this study. After ventilation there were no significant changes in the hematocrit, total protein, or serum electrolytes and osmolarity in these infants.

Table 1 shows the complete flow measurements in all of the infants during the control period. The mean cardiac output was $159.0 \mathrm{ml} / \mathrm{min} / \mathrm{kg}$ and ranged from 44.9 to 326.9 $\mathrm{ml} / \mathrm{min} / \mathrm{kg}$. During the control period the total renal blood flow was $2.46 \mathrm{ml} / \mathrm{min} / \mathrm{g}$ kidney and represented $11.6 \%$ of the actual cardiac output. This percentage of cardiac output to the kidney is similar to that reported for 8-day-old rhesus monkeys but slightly higher than that reported in seven day old piglets (7). During the control period, the flow to the inner cortex was $2.54 \mathrm{ml} / \mathrm{min} / \mathrm{g}$. The difference between the mean values was highly significant $(P<0.001)$. The ratio of outer cortical to inner cortical flow during the control period was 2.56 and demonstrates a preponderance of outer cortical flow.

The effect of IPPV on flow measurements is shown in Table 2. Mean cardiac output fell to $100.6 \mathrm{ml} / \mathrm{min} / \mathrm{kg}$ and was significantly different from the control value $(P<0.001)$. Total renal blood flow after stress was $0.91 \mathrm{ml} / \mathrm{min} / \mathrm{g}$ and was reduced to $7.1 \%$ of the actual cardiac output. The percentage of cardiac output to the kidneys and the total renal blood flow were significantly different from control values. The outer cortical and inner cortical flows after ventilation were 1.01 and $1.66 \mathrm{ml} / \mathrm{min} / \mathrm{g}$, respectively. These changes in intrarenal flows were highly significant $(P<0.001)$. The ratio of outer cortical to inner cortical flow after ventilation was 0.64 and was significantly different from the control value $(P<0.001)$.

Table 3 shows the mean arterial pressure and renal vascular resistance before and after ventilation. Mean aortic pressure did not change significantly after ventilation. However, the rise in renal vascular resistance to $54.41 \mathrm{~mm} \mathrm{Hg} / \mathrm{ml} / \mathrm{g}$ over the control value of $27.12 \mathrm{~mm} \mathrm{Hg} / \mathrm{ml} / \mathrm{g}$ was highly significant $(P<0.005)$.

\section{DISCUSSION}

Renal blood flow in early infancy has been studied by use of p-aminohippurate (PAH) clearances. Calcagno and Rubin (4) demonstrated in human infants up to 3 months of age that renal extraction of $\mathrm{PAH}$ was approximately $30 \%$ less than the mean adult value of 0.95 . We examined this problem (16) by measuring PAH extraction in infant puppies. We found that similar to the human infant, the extraction ratio of PAH in puppies is significantly less than that in the adult dog. When PAH clearances were measured while increasing the tubular load of PAH 10-fold, no change in extraction or clearance of PAH was observed. This suggested that the low extraction of PAH in puppies was not due to a limitation in tubular transport capacity but possibly to a failure of a large fraction of blood to contact PAH transport sites in the proximal tubule. We proposed that this was evidence that a large portion 
of total renal blood flow in puppies may perfuse the juxtamedullary glomeruli whose efferent arterioles supply the vasa rectae and permit a portion of postglomerular blood to bypass contact with the proximal tubule where PAH is mainly extracted.

The importance of intrarenal blood flow distribution on overall renal function is not clear. The controversial demonstration by Horster and Thurau of different functional capacities between subcapsular and juxtamedullary nephrons suggested a theoretically important role for relative flow to each nephron group on overall renal function. Thus, although total renal blood flow is low in early infancy, the extent and character of renal function during this period may reflect intrarenal distribution of blood flow as well as total renal blood flow. In this study we used radiolabeled microspheres to measure intrarenal blood flow in infant nonhuman primates. The use of radioactive microspheres for measurement of intrarenal distribution of blood flow has been the subject of several recent reviews (12). The factors that are thought to be related to the suitability of this method include the effect of microspheres on renal histology, on systemic variables such as blood pressure, cardiac output and pulse rate, on renal function, and the rheology of the microspheres. In separate control studies, we found no effect on renal blood flow of three sequential injections of different nucleotides. Rheologic studies have demonstrated that microsphere size and density may play a role in the apparent distribution of blood flow. Katz et al. (12) reported that in adult dogs, as microsphere size is progressively increased from 10 to $50 \mu \mathrm{m}$, there is an increasingly disproportionate delivery of microspheres to the subcapsular or outer cortical area. McNay and Abe (15), however, found no difference in distribution of flow to four different layers of the renal cortex in dogs using microspheres of 18,27 , and $36 \mu \mathrm{m}$ mean diameter. Buckberg et al. (3) have indicated that the variability of distribution of microspheres to any vascular region should approximate a Poisson distribution. They suggest therefore that in calculation of regional distribution of blood flow, the number of microspheres required in each organ or organ segment is equally important to microsphere size. Since it has been shown that larger microspheres as used in our study tend to overestimate outer cortical flow due to axial streaming, the demonstration of a reversal of intracortical flow with a significant decrease in outer cortical flow in response to IPPV in our experiments strongly suggest that microsphere size and axial streaming did not play a major role in our results as these factors would tend to produce the opposite effect. However, we cannot discount the possibility that the fall in renal blood flow resulted in decreased skimming and thus a tendency of the microspheres to have a more central lodging. A separate experiment is necessary to properly evaluate this effect on microsphere distribution. Because the decreased renal blood flow was induced by IPPV, its effect on intrarenal flow is directly related to IPPV and support our contention that IPPV influence intrarenal flow.

The intrarenal distribution of renal blood flow in the control period is shown in Table 1 . The mean outer cortical flow was $4.23 \mathrm{ml} / \mathrm{min} / \mathrm{g}$, whereas the mean inner cortical flow was $2.54 \mathrm{ml} / \mathrm{min} / \mathrm{g}$. The ratio of outer to inner cortical flow was 2.56 and a preponderance of outer cortical flow in the control period was clearly evident. The ratio of outer to inner cortical flow of 2.56 is similar to that of 2.10 which can be calculated from microsphere studies by Jose and colleagues in infant puppies (11).

In the present experiments redistribution of intrarenal blood flow was demonstrated in infant primates in response to IPPV. After the IPPV there was a significant fall in cardiac output and in total renal blood flow. The total renal blood flow after ventilation was $0.91 \mathrm{ml} / \mathrm{min} / \mathrm{g}$ and was only $7.1 \%$ of the actual cardiac output. The renal vascular resistance after ventilation significantly increased from 27.12 to $56.41 \mathrm{~mm} \mathrm{Hg} / \mathrm{ml} / \mathrm{g}$. Thus, the significant fall in renal blood flow was due to both a fall in cardiac output and to a rise in renal vascular resistance. The mean outer cortical flow after IPPV was $1.01 \mathrm{ml} / \mathrm{min} / \mathrm{g}$ and the inner cortical flow was $1.66 \mathrm{ml} / \mathrm{min} / \mathrm{g}$. The ratio of outer cortical to inner cortical flow was 0.64 . The reversal of inner cortical and outer cortical flows clearly indicated a redistribution of cortical flow as well as a total reduction in cortical flow. Thus assisted ventilation must be included in the physiologic and experimental conditions that are thought to result in redistribution of intrarenal blood flow.

The afferent pathways that resulted in redistribution of intrarenal blood flow following IPPV in these studies are not known. Many conditions have been reported to result in a redistribution of renal blood flow. These include hemorrhage (14), acidosis (2), changes in hematocrit (17), and external perfusion of a kidney (19). Carriere and Biron (5) and Carriere and Friborg (6) have studied intrarenal blood flow distribution during angiotensin infusion. These investigators reported that subcapsular or outer cortical vessels in the kidney are more sensitive to angiotensin infusion than juxtamedullary vessels. In their studies infusion of angiotensin produced a greater decrease in outer cortical blood flow and relative preservation of inner cortical flow. These findings may play a role in the interpretation of the results demonstrated in our studies. Alterations in epinephrine and other steroid production or metabolism are known to occur in asphyxia, hypoxia, and nonspecific stress (21). It can be speculated that in our unsedated awake infants the process of assisted ventilation was stressful. It is possible that increased epinephrine and other adrenal steroids occurred in response to this stress. If increased epinephrine production occurred, this may have had a greater effect on the superficial capsular arteries which supply the outer cortical nephrons and a redistribution of intrarenal blood flow would result. Since there was not a significant change in blood gases after ventilation, the stimulus for any surfiet of epinephrine in our experiments would have to be termed nonspecific stress. The studies of Logan et al. (14) also demonstrate the effect of nonspecific stress on renal blood flow distribution. These authors showed that simple cannulation of the external carotid artery in dogs could result in a redistribution of intrarenal blood flow.

The clinical implications of these studies are highly speculative; however, any decrease in urine flow in patients on assisted respiration must be interpreted in view of this data. Persistent oliguria in these patients that was previously thought to be secondary to blood loss, surgical procedures, or to prerenal volume depletion, may in fact reflect redistribution of intrarenal flow to juxtamedullary nephrons which may at least theoretically result in diminished urine flow. It has been reported that IPPV is associated with the syndrome of inappropriate antidiuretic hormone secretion $(13,20)$. These patients had decreased urine flow and water retention secondary to increased amounts of ADH. Although ADH levels were not measured, the present studies suggest that water and salt retention in response to ADH may in part be a result of redistribution of renal blood flow induced by $\mathrm{ADH}$. Humphries et al. (10) has shown that PAH clearance falls when vasopressin is infused into dogs undergoing water diuresis. A redistribution of renal blood flow to juxtamedullary nephrons with poor PAH extraction might result in a fall in PAH clearance. It can be speculated from our data that vasopressin may effect distribution of renal blood flow as well as alter membrane permeability.

\section{SUMMARY}

The present data indicate that intrarenal distribution of renal blood flow in infant primates is similar to that in the adult. There is a preponderance of outer cortical over inner 
cortical flow. This intrarenal blood flow is apparently sensitive to extrarenal stimuli as positive pressure ventilation causes a reversal of this flow. The direct application of this data to clinical conditions is difficult. However, these data suggest that low urine flow rates in human infants on ventilation might be secondary to local intrarenal blood flow changes induced by assisted ventilation.

\section{REFERENCES AND NOTES}

1. Behrman, R. E., and Lee, M. H.: Organ blood flows of the fetal, newborn and adult rhesus monkey. Biol. Neonate, 18: 330 (1971).

2. Bersentes, T. J., and Simmons, D. H.: Effects of acute acidosis on renal hemodynamics. Amer. J. Physiol., 212: 633 (1967).

3. Buckberg, G. D., Luck, J. C., Payne, D. B., Hoffman, J. I. E., Archie, J. P., and Fixler, D. E.: Some sources of error in measuring regional blood flow with radioactive microspheres. $J$. Appl. Physiol. 31: 598 (1971).

4. Calcagno, P. L., and Rubin, M. J.: Renal extraction of paraminohippurate in infants and children. J. Clin. Invest., 42: 1632 (1963).

5. Carriere, S., and Biron, P.: Effect of angiotensin 1 on intrarénal blood flow distribution. Amer. J. Physiol., 219: 1642 (1970).

6. Carriere, S., and Friborg, J.: Intrarenal blood flow and PAH extraction during angiotensin infusion. Amer. J. Physiol., 217 . 1708 (1969).

7. Cruskin, A. B., Edelmann, C. M., Jr., and Yuan, S.: Maturational changes in renal blood flow in piglets. Pediat. Res., 4: 7 (1970).

8. Hollenberg, A. C., and Herd, J. A.: The renal circulation. New Engl. J. Med., 47: 455 (1968).

9. Horster, M., and Thurau, K.: Micropuncture studies on the filtration rate of single superficial and juxtamedullary glomeruli in the rat kidney. Pflugers Arch. Gesamte Physiol. Menschen Tiere, 301: 162(1968).

10. Humphries, M. H., Friedler, R. M., and Early, L. E.: Naturesis produced by vasopressin or hemorrhage during water diuresis in the dog. Amer. J. Physiol., 219: 658 (1970)

11. Jose, P. A., Logan, A. G., Slotkoff, L. M., Lilienfield, L. S.,
Calcagno, P. L., and Eisner, G. M.: Intrarenal blood flow distribution in canine puppies. Pediat. Res., 5: 335 (1971).

12. Katz, M. A., Blantz, R. C., Rector, F. C., Jr., and Seldin, D. W. Measurement of intrarenal blood flow. I. Analysis of microsphere method. Amer. J. Physiol., 220: 1903 (1971).

13. Khambatta, H. J., and Baratz, R. A.: IPPB, plasma ADH, and urine flow in conscious man. J. Appl. Physiol., 33: 362 (1972).

14. Logan A., Jose, P., Eisner, G., Lilienfield, L., and Slotkoff, L. Intracortical distribution of renal blood flow in hemorrhagic shock in dogs. Circ. Res., 29: 257 (1971).

15. McNay, J. L., and Abe, Y.: Pressure-dependent heterogeneity of renal cortical blood flow in dogs. Circ. Res., 27: 571 (1970).

16. Moore, E. S., Satrasook, S. S., Fine, B. P., Katz, M. C., and Edelmann, C. M., Jr.: Renal PAH extraction in puppies (Abstract), p. 119. In: Proceedings of the 39 th Annual Meeting, Society for Pediatric Research, Atlantic City, N.J., 1969.

17. Navar, L. G., Guyton, A. C., and Langston, J. B.: Effect of alterations in plasma osmolarity on renal blood flow autoregulation. Amer. J. Physiol., 211: 1387 (1966).

18. Rudolph, A. M., and Heymann, M. A.: Circulation of the fetus in utero: Methods for studying distribution of blood flows, cardiac output and organ blood flow. Circ. Res., 21: 163 (1967).

19. Rudolph, A. M., and Heymann, M. A.: Measurement of flow in perfused organs, using microsphere technique, pp. 112-127. In: Proceedings of the 4th Symposium, Karolinska Symposia on Research Methods in Reproductive Endocrinology, 1971.

20. Sladen, A., Laver, M. B., and Pontoppidan, H.: Pulmonary complications and water retention in prolonged mechanical ventilation. New Engl. J. Med., 279: 448 (1968).

21. Wurtman, R. J.: Catecholamines. New Engl. J. Med, 273: 637 (1965).

22. Model 25601, Nuclear-Chicago, Corporation, Des Plaines, Ill.

23. Bausch and Lomb, Rochester, N.Y.

24. Presented in part at the annual meeting of the Society for Pediatric Research, Atlantic City, May 25, 1972.

25. This research was supported by Public Health Service Grant no. RO-1-HL-13633, Public Health Service General Research Support Grant no. FR 5369, and the State of Illinois.

26. Requests for reprints should be addressed to: E. S. Moore, M.D. Michael Reese Hospital and Medical Center, 2929 S. Ellis Ave. Chicago, Ill. 60616 (USA).

27. Accepted for publication May 2, 1974.

Printed in U.S.A.

Antipyrine placenta

fetus free fatty acids

\title{
Transfer across Perfused Human Placenta. III. Effect of Chain Length on Transfer of Free Fatty Acids
}

\author{
JOSEPH DANCIS, ${ }^{(25)}$ VALERIE JANSEN, HERBERT J. KAYDEN, LORING BJORNSON, \\ AND MORTIMER LEVITZ \\ Departments of Pediatrics, Obstetrics and Gynecology, and Medicine, New York University School of Medicine, \\ New York, New York, USA
}

$\checkmark$

Extract

Human placentas were perfused in vitro with straight chain, even-numbered free fatty acids (FFA) and the transfer rates from maternal to fetal circulation were measured. The transfer rates increased logarithmically as chain length decreased. The clearances, calculated as percentage of clearance of antipyrine were: palmitic acid, 4\%; myristic acid, $10 \%$; lauric acid, $16 \%$; decanoic acid, $18 \%$; octanoic acid, $50 \%$; hexanoic acid, $64 \%$.

\section{Speculation}

Transfer of hydrophobic materials through the placenta is a complex process which is probably affected by many factors. The present studies with FFA suggest that, for these compounds, protein binding may be particularly significant. If 